ECCOMAS

Proceedia
COMPDYN 2021

$8^{\text {th }}$ ECCOMAS Thematic Conference on Computational Methods in Structural Dynamics and Earthquake Engineering

M. Papadrakakis, M. Fragiadakis (eds.)

\title{
EVALUATION OF A NUMERICAL MODELLING APPROACH FOR THE SIMULATION OF RETROFITTED RC ELEMENTS
}

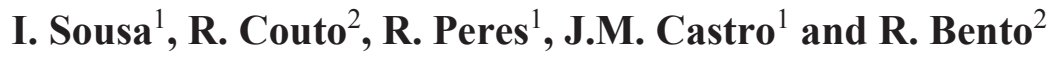 \\ ${ }^{1}$ CONSTRUCT \\ Faculdade de Engenharia da Universidade do Porto \\ Rua Dr Roberto Frias, $\mathrm{s} / \mathrm{n}$ \\ e-mail: \{inessousa, ritaperes, miguel.castro\}@fe.up.pt \\ ${ }^{2}$ CERIS \\ Instituto Superior Técnico, Universidade de Lisboa \\ Av. Rovisco Pais, 1 \\ e-mail: \{rita.g.couto, rita.bento\}@tecnico.ulisboa.pt
}

\begin{abstract}
The majority of the RC building stock in large cities consist of old buildings where most of them were designed with codes without any seismic provisions, thus leading, most likely, to important seismic vulnerabilities. Good knowledge about the building properties and vulnerabilities and, more importantly, on how to model the behaviour of the most relevant components, is fundamental to help analysts and practitioners in the assessment and strengthening of existing $R C$ buildings.

This paper focuses on the numerical modelling of strengthening solutions for RC buildings, with the objective of defining a modelling approach that accurately captures the behaviour of retrofitted elements. To achieve this goal, retrofitted elements are simulated through distributed plasticity models and their seismic performance compared with the most recent experimental data available on this topic.

As a case study, an existing reinforced concrete building with typical properties of non-ductile buildings in Portugal is modelled and analysed through nonlinear static analysis to determine the building structural weaknesses. The retrofitting interventions were designed based on code recommendations.
\end{abstract}

Keywords: RC structures retrofitting, carbon fibre-reinforced polymer (CFRP), numerical modelling of strengthening solutions, seismic performance improvement. 


\section{INTRODUCTION}

A significant number of existing reinforced concrete (RC) buildings in earthquake-prone locations require seismic retrofitting since the majority of these buildings do not meet the current seismic assessment code requirements. Several deficiencies are commonly found in this type of buildings, such as poor reinforcement details, lack of adequate transverse reinforcement and insufficient confinement reinforcement at potential plastic hinges areas. These characteristics decrease the RC members' strength to shear forces, thus leading to premature brittle failures, as have been observed on field surveys performed in areas affected by earthquakes [1]-[4].

Among the different strengthening techniques, the use of fibre-reinforced polymer (FRP) composites has become progressively suitable due to the fast installation, minimal modification to the existing architecture and satisfactory mechanical properties. Moreover, as a lightweight material, FRP does not modify the cross sectional properties of elements or the structure mass [5]. Accordingly, the seismic performance of RC elements retrofitted with FRP has been the subject of extensive investigation [6]-[13]. The majority of the studies focused on experimental campaigns carried out on RC elements retrofitted with FRP. Nonetheless, the present study will give emphasis to the modelling aspects of such type of intervention.

Since it is acknowledged that vulnerable $\mathrm{RC}$ buildings require retrofit, it is crucial for practitioners to have the means for modelling, with accuracy, the behaviour of the existing structures, and, more importantly, to have the tools to correctly model the response of the existing retrofitted structural elements. Therefore, the first part of this paper focuses on the numerical simulation of a RC column using the OpenSees [14] software, with the aim of validating the modelling approach with experimental data.

The second part of the study consists of the numerical modelling of a structure representative of the Portuguese building stock in the 1950s, also using OpenSees, before and after the retrofitting intervention. The structure's capacity is estimated with nonlinear static analysis and its seismic performance is evaluated through the calculation of the demand/capacity ratios recommend by Part 3 of Eurocode 8 (EC8-3) [15]. The initial assessment indicates brittle and ductile failure modes in some structural elements (columns and walls). A strengthened solution employing CFRP is designed and numerically implemented in the structural model. Afterwards, a new seismic evaluation is carried out and the structure's safety assessed once more. The results demonstrate the feasibility and effectiveness of the CFRP as a strengthening solution to eliminate brittle and ductile mechanisms.

\section{MODELLING APPROACH}

This section introduces a numerical modelling approach to simulate the behaviour of FRP in RC elements using OpenSees, which will be validated through comparison of numerical with experimental data.

\subsection{Experimental data}

In order to fulfil the goal of accurately representing the real behaviour of retrofitted RC elements with FRP, first it was necessary to select a RC element tested experimentally from the literature. The specimen used in this paper is available in a study performed by Del Zoppo et al. [16] and consists of a RC column tested under axial load and cyclic lateral loading. The column was designed to old construction practice in order to be representative of real existing structures. As such, the specimen is characterized by poor quality concrete, no longitudinal 
reinforcement in the cross-section secondary direction and the transverse reinforcement details are not compliant with current standards.

The test specimen has a square cross-section $300 \times 300 \mathrm{~mm}^{2}$ with six $\phi 18 \mathrm{~mm}$ longitudinal steel rebars and $\phi 8 \mathrm{~mm}$ ties spaced $150 \mathrm{~mm}$ apart. In the zone of the load application, the spacing between ties was reduced to avoid localized damages. The column height is $1800 \mathrm{~mm}$, and the lateral load was applied at a distance of $1500 \mathrm{~mm}$ from the foundation block. The average concrete compressive strength for the retrofitted specimen is $f_{c}=14.9 \mathrm{MPa}$, whilst the average yielding strength of the steel bars in both longitudinal and transverse reinforcement is $f_{y}$ $=531 \mathrm{MPa}$.

To what concerns the retrofit solution adopted, the column was wrapped with uniaxial carbon fibre reinforced polymers (CFRP) along $500 \mathrm{~mm}$ from the column base, which corresponds to the location of the plastic hinge development. The geometric properties and the reinforcement details are illustrated in Figure 1. In addition, Erro! A origem da referência não foi encontrada. shows the mechanical properties of the CFRP.

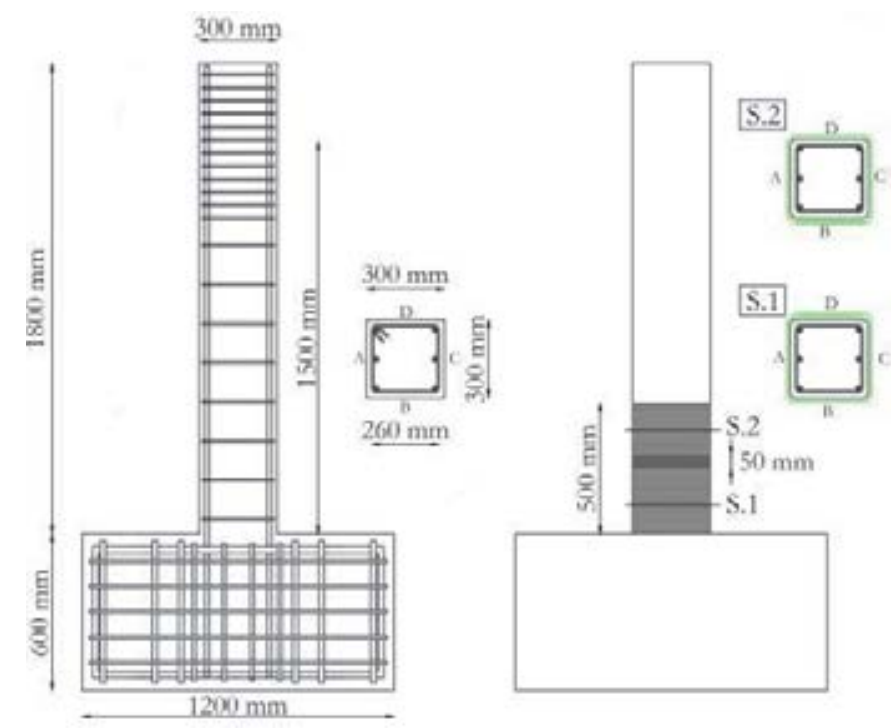

Figure 1: Specimen geometry and strengthening configuration (adapted from [16]).

\begin{tabular}{lllll}
\hline Material & $\begin{array}{l}\text { Number of } \\
\text { plies }\end{array}$ & $\begin{array}{l}\text { Thickness } \\
(\mathrm{mm})\end{array}$ & $\begin{array}{l}\text { Elastic modulus } \\
(\mathrm{GPa})\end{array}$ & $\begin{array}{l}\text { Ultimate strain } \\
(\%)\end{array}$ \\
\hline CFRP & 1 & 0.33 & 230 & 1.3 \\
\hline
\end{tabular}

Table 1: Carbon fibres material properties[in Del Zoppo et al. [16]].

Regarding the axial load applied, the specimen was subjected to a constant axial load ratio of 0.1 , such that $v=N / A_{c} f_{c}$, where $N$ is the axial load, $A_{c}$ is the concrete gross area and $f_{c}$ is the mean cylindrical concrete strength. 


\subsection{OpenSees modelling}

As mentioned before, the modelling of the specimen was conducted using OpenSees, an open-source software framework developed to simulate the behaviour of structures subjected seismic actions. There are two models that can be employed in OpenSees to simulate the inelastic response of RC elements: distributed or concentrated plasticity approaches. In this study, the column was modelled trough a distributed plasticity approach, using the nonlinearBeamColumn command and considering a force-based formulation with four elements, each with five integrations points.

The element's cross-section was represented by a fibre section, which in turn was subdivided into smaller fibre sections. These fibre objects are associated with uniaxial materials that express the stress-strain relationship of concrete, steel and CFRP. The behaviour of both the cover and core concrete fibres was simulated adopting the model suggested by Popovics [17], (Concrete 04 material in OpenSees) whilst the steel was modelled through a uniaxial bilinear hysteretic material object, translated by the command uniaxialMaterial Hysteretic. The stress and strain values of the steel rebars were input into this command, which also allows for the consideration of the pinching effect. Finally, the contribution of the CFRP was achieved by adding the effect of the confinement provided by the retrofit intervention.

The effect of the confinement provided by the transverse reinforcement and the CFRP acting simultaneously was determined through the confinement model proposed in Part 3 of Eurocode 8 (EC8-3) [15]. The strength of confined concrete, $f_{c c}$, the strain at which the strength takes place, $\varepsilon_{c c}$, and the ultimate strain of the extreme fibre of the compression zone, $\varepsilon_{c u}$., are given by the expressions (1), (2) and (3), respectively.

$$
\begin{gathered}
f_{c c}=f_{c}\left[1+3.7\left(\frac{\alpha \rho_{s x} f_{y w}}{f_{c}}\right)^{0.86}\right] \\
\varepsilon_{c c}=\varepsilon_{c 2}\left[1+5\left(\frac{f_{c c}}{f_{c}}-1\right)\right] \\
\varepsilon_{c u}=0.004+0.5 \frac{\alpha \rho_{s x} f_{y w}}{f_{c c}}
\end{gathered}
$$

In the expressions above, $f_{c}$ is the concrete compressive strength, $f_{y w}$ is the transverse reinforcement yield strength, $\alpha$ is the confinement effectiveness factor, $\rho_{s x}$ is the ratio of transverse reinforcement and $\varepsilon_{c 2}$ is the strain at which $f_{c}$ takes place of unconfined concrete, taken as 0.002 . The mechanical properties adopted for all materials are shown in Erro! A origem da referência não foi encontrada. The concrete tensile strength was taken as $10 \%$ of the compressive strength.

\begin{tabular}{lllll}
\hline Material & & $f_{c}(\mathrm{MPa})$ & $\varepsilon_{c}(\%)$ & $\varepsilon_{c u}(\%)$ \\
\hline Concrete (core) & $\phi 8 / / 150$ & 16.7 & 0.32 & 1.21 \\
Concrete (core) & $\phi 8 / / 50$ & 21.8 & 0.67 & 3.5 \\
\hline & & $f_{y}(\mathrm{MPa})$ & $f_{u}(\mathrm{MPa})$ & $E_{s}(\mathrm{GPa})$ \\
\hline Steel & 531 & 627 & 210 \\
\hline & & $f_{c}(\mathrm{MPa})$ & $\varepsilon_{c}(\%)$ & $\varepsilon_{c u}(\%)$ \\
\hline CFRP & 24.6 & 8.4 & 4.41 \\
\hline
\end{tabular}


Table 2: Mechanical properties of the materials used in the modelling.

The adequacy of this modelling approach was evaluated through comparison of the results from cyclic pushover analysis with the experimental test data. The results obtained are illustrated in Figure 2, where the black dashed line corresponds to the experimental data and the grey cyclic curves refers to the OpenSees results. As it can be seen, a good agreement between the experimental data and numerical modelling was achieved, not just in terms global strength but also in what concerns the ability of the model in simulating the pinching effects. These results indicate that this type of approach is adequate to model FRP interventions in existing $\mathrm{RC}$ buildings.

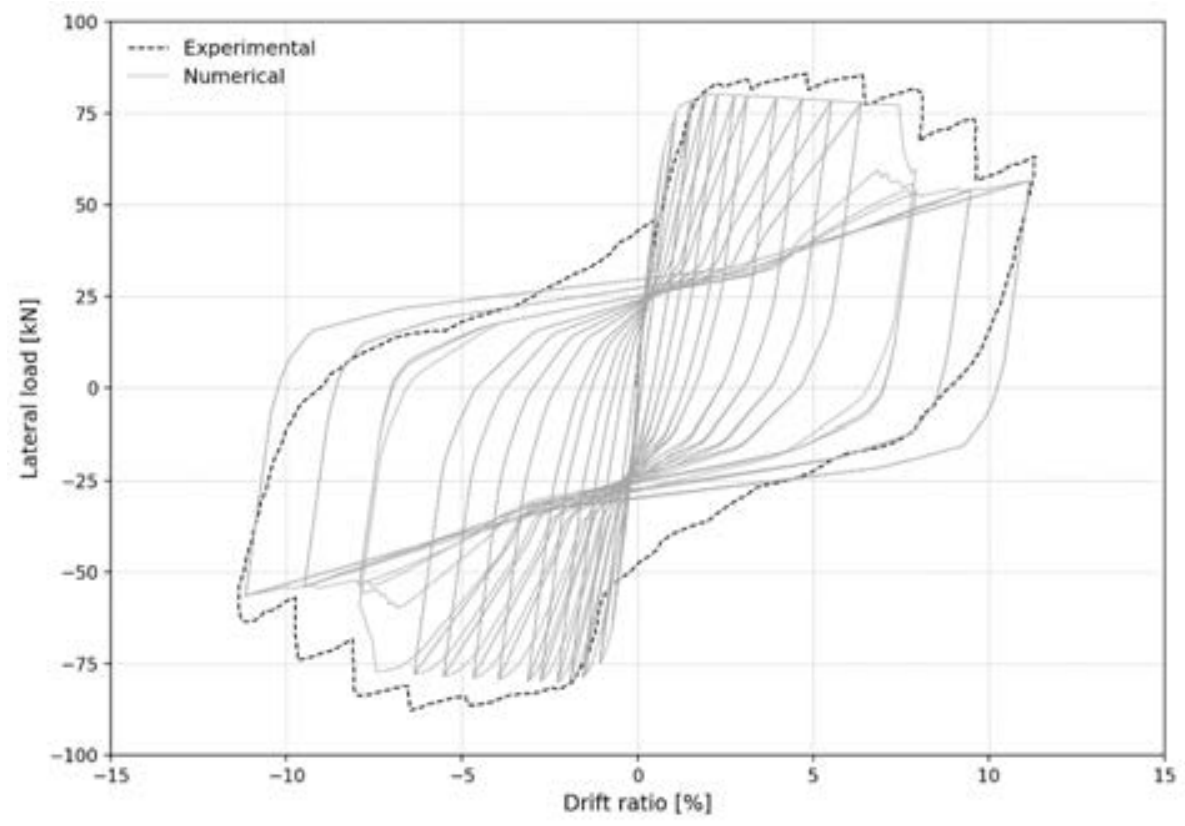

Figure 2: Comparison between experimental results and OpenSees.

An example of this FRP modelling approach application into a real existing building is described in the following sections of this paper.

\section{CASE STUDY APPLICATION}

\subsection{Description of the building and structural modelling}

The RC building selected is a five-storey wall-frame RC building, built in the 1950s. The building has a total height of $15.4 \mathrm{~m}$ with a typical floor heigh of $3.0 \mathrm{~m}$, except for the ground floor, for which the height is equal to $3.4 \mathrm{~m}$. It has three and five frames in $\mathrm{X}$ and $\mathrm{Y}$ directions, respectively. A shear wall is positioned at the middle of the building, oriented in the X direction, on the first three storeys. The plan and elevation views of the building are shown in Figure 3.

The information about the section geometric properties and reinforcement ratios variation of the building structural elements is presented in Erro! A origem da referência não foi encontrada.. 

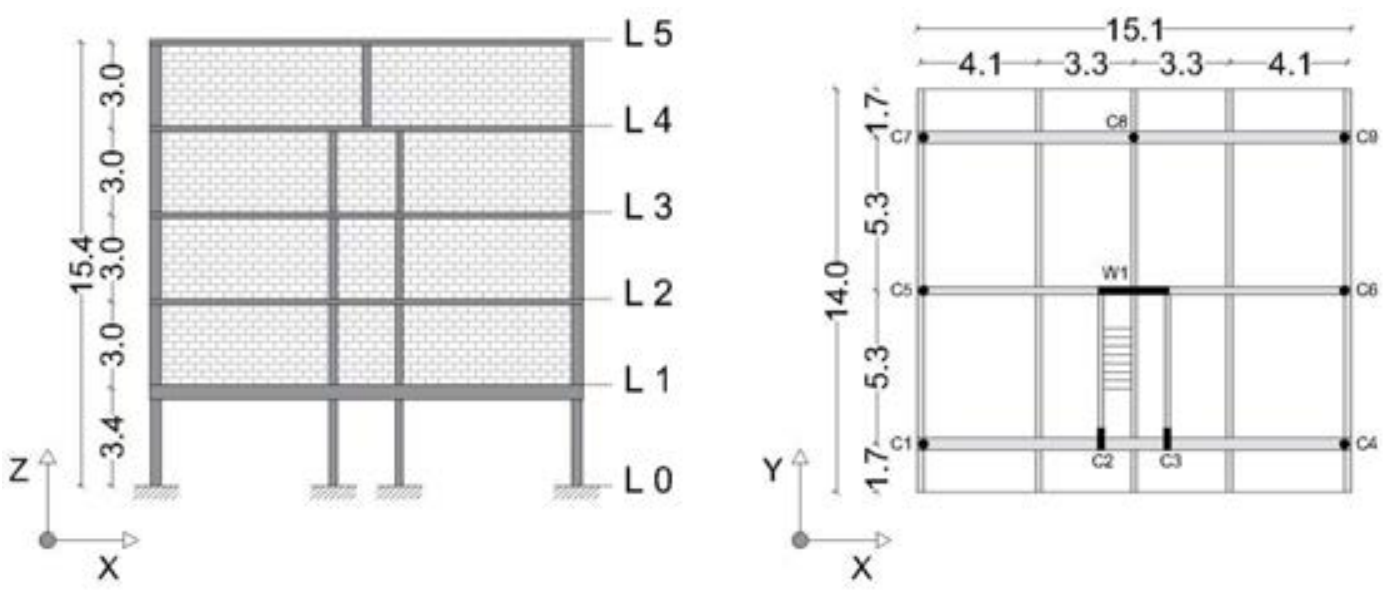

Figure 3: Elevation and plan of the selected building.

\begin{tabular}{|c|c|c|c|}
\hline Element & Columns & Beams & Walls \\
\hline Dimensions $(\mathrm{cm})$ & $23 \times 25-25 \times 87$ & $13 \times 31-25 \times 68$ & $250 \times 25$ \\
\hline Cross Section $\left(\mathrm{cm}^{2}\right)$ & $575-2175$ & $403-1700$ & 6250 \\
\hline Longitudinal rebar $\left(\mathrm{cm}^{2}\right)$ & $0.63-7.29$ & $\begin{array}{l}\mathrm{T}: 2.26-29.76 \\
\mathrm{~B}: 3.93-33.58\end{array}$ & 15.78 \\
\hline Transversal rebar $\left(\mathrm{cm}^{2}\right)$ & $0.18-0.71$ & 1.48 & 3.15 \\
\hline Spacing of stirrups $(\mathrm{cm})$ & $5-19$ & $20-50$ & 15 \\
\hline
\end{tabular}

Table 3: Sectional geometrical properties and minimum/maximum reinforcement ratios of the structural elements ( $T$ and $B$ refer to top and bottom beam reinforcements, respectively).

The building was modelled and analysed with OpenSees. All the structural elements were modelled using the nonlinearBeamColumn command and considering a force-based formulation considering one element per beam, column and wall. The concrete and steel stress-strain relationships adopted at the fibre level were the ones mentioned in the previous section. The mean values of the material properties used in the model are listed in Table 4. The behaviour of the smooth rebars was modelled by modifying the steel constitutive law, reducing the Young's Modulus and maximum strength of the reinforcing steel to simulate the increase in member flexibility due to strain penetration effects [18].

The torsional stiffness was incorporated in the model by computing the elements torsional stiffness and assigning it through the section aggregator program command, while the rigid inplane stiffness of the floor slab was modelled considering a rigid diaphragm multi-point constraint, through the program command rigid diaphragm. Second-order effects were accounted for in the model by adopting a P-Delta geometric transformation for the columns and wall. The infill panels were also modelled by assuming the two-diagonal truss approach established in [19]. The mass, which was obtained through the conversion of dead and live loads, was lumped at the centre of mass at each floor level. The dead loads include the self-weight of the RC elements, masonry infills and coatings, i.e., $8 \mathrm{kN} / \mathrm{m}^{2}$, while the live loads have been defined according to Part-1 of Eurocode 8 [20]. The fundamental periods of vibration of the building are $0.31 \mathrm{~s}$ and $0.41 \mathrm{~s}$ in $\mathrm{X}$ and $\mathrm{Y}$ directions, respectively. 


\begin{tabular}{|c|c|c|c|c|}
\hline Concrete & $f_{c}(M P a)$ & $\mathcal{E}_{c}(\%)$ & $\mathcal{E}_{c u}(\%)$ & $E_{c}(G P a)$ \\
\hline Cover & 28 & 2 & 4 & 30 \\
\hline Core & 28 & 2 & 200 & 30 \\
\hline Steel & $f_{y}(M P a)$ & $f_{u}(M P a)$ & $\mathcal{E}_{\text {su }}(\% \mathrm{o})$ & $E_{s}(G P a)$ \\
\hline Ribbed rebar & 370 & 360 & 240 & 210 \\
\hline Smooth rebar & 222 & 216 & 168 & 126 \\
\hline Masonry & $G_{w}(G P a)$ & $\alpha$ & $\tau_{\mathrm{cr}}$ & $E_{w}(G P a)$ \\
\hline Infills & 1240 & 0.05 & 280 & 4092 \\
\hline
\end{tabular}

Table 4: Material properties

A nonlinear static analysis was performed to evaluate the lateral capacity of the structure. The analysis was performed in both the $\mathrm{X}$ and $\mathrm{Y}$ directions, with positive and negative signs and, despite the slight asymmetry in the $\mathrm{Y}$ direction of the building, no significant differences were observed between the positive and the negative orientations. Two load patterns were considered: i) a modal load pattern, proportional to the fundamental mode of vibration, and ii) a uniform load pattern, proportional to the masses of the floors. Only the results corresponding to the modal pattern were considered since they correspond to a capacity curve with lower resistance and, consequently, more restrictive in terms of performance.

\subsection{Seismic assessment}

The seismic safety of the buildings was evaluated in terms of the demand/capacity ratio (DCR) for each vertical structural element (columns and walls) following the procedure recommended in EC8-3, which consists of comparing the chord rotation and shear demand with the capacity values of ultimate chord rotation and shear strength. The target displacement was determined with the N2 method, also as prescribed in EC8-3.

As established in EC8-3, the return periods to consider in the assessment of the existing buildings are: 73, 308 and 975 years for the damage limitation (DL), the significant damage (SD) and the near-collapse (NC) limit states, respectively. According to each of the limit states, the reference ground acceleration $\left(\mathrm{a}_{\mathrm{gR}}\right)$ is then multiplied by a coefficient. Only the response spectrum for the Type 1 seismic action (far-field earthquake) was considered, therefore, the $a_{\mathrm{gR}}$ is $0.15 \mathrm{~g}$ (Lisbon, Zone 1.3). The Portuguese Annex of EC8-3 [21] recommends that, for existing residential buildings, the assessment should be performed considering only the significant damage (SD) limit state.

Figure 4 shows the pushover curves obtained for the $\mathrm{X}$ and $\mathrm{Y}$ directions with the indication of the target displacement attainment at the SD limit state. It can be observed that, in the $\mathrm{X}$ direction, brittle and ductile failures occur almost simultaneously before target displacement is reached. In the Y direction, the structure exhibits lower capacity, due to the absence of RC walls oriented in this direction, and also experiences a brittle failure before the target displacement is reached. In conclusion, the brittle failure was the conditioning mechanism for both directions, 
corresponding to a displacement of $0.0036 \mathrm{~m}$ and $0.0079 \mathrm{~m}$ for the $\mathrm{X}$ and $\mathrm{Y}$ direction, respectively. The occurrence of this type of mechanism at early stages of lateral deformation is common in old RC buildings designed to resist gravity loads, as verified by [22].

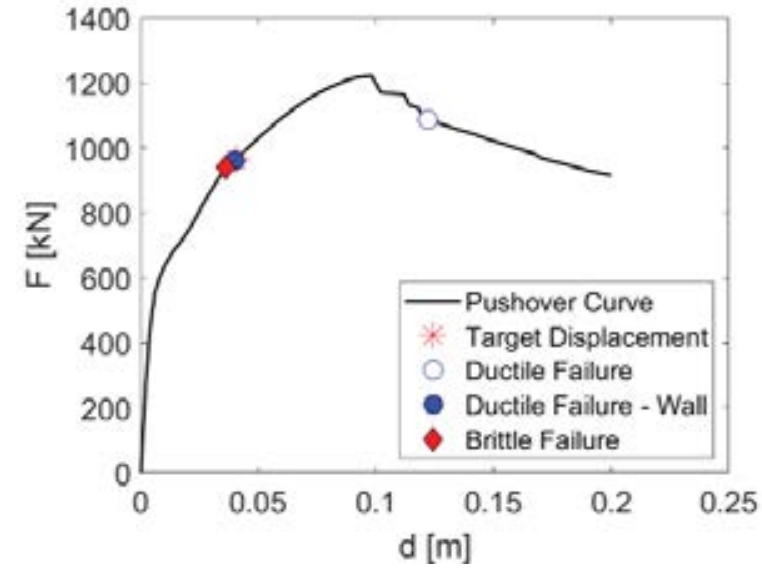

(a)

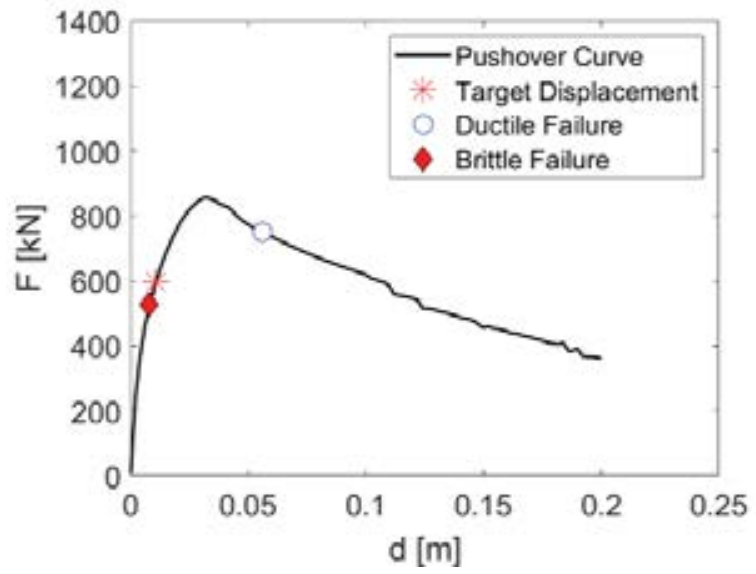

(b)

Figure 4: Pushover curves for the (a) X and (b) Y direction with the indication of the target displacement and failure mechanisms.

Figure 5 illustrates the location and type of damage experienced by the vertical $\mathrm{RC}$ elements when the displacement that corresponds to SD limit state is reached. As it can be seen, in direction X, some elements (columns and wall) are simultaneously affected by brittle and ductile failures on the first two storeys, while Y direction, the elements are only affected by a brittle mechanism on the ground storey.
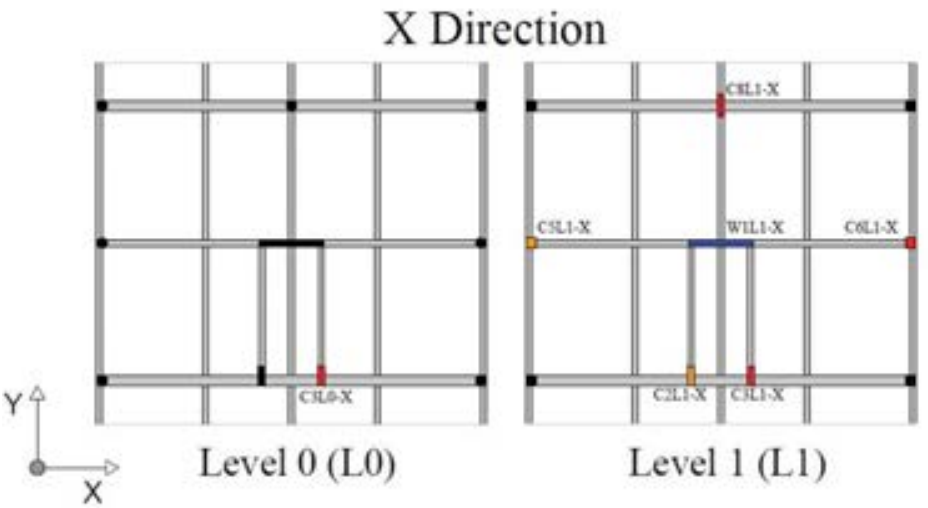

Y Direction

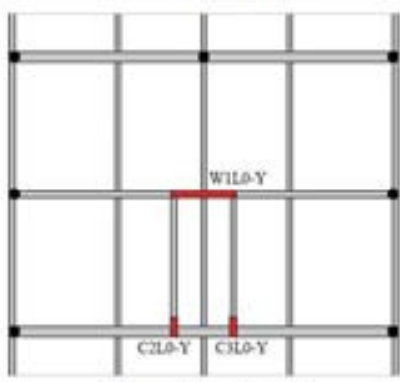

Level 0 (L0)

Figure 5: Location and indication of the type of damage on the vertical RC elements.

The columns C5 and C2, located in level 1, were also included in Figure 5 as "Reaching Brittle Failure" because the value of the demand/capacity ratio (DCR) associated shear failure assessment was remarkably close to the unit, which means these elements were near to develop a brittle mechanism. 


\section{RETROFITTED BUILDING}

\subsection{Design and modelling of the retrofitting solution}

The initial seismic assessment performed on the case study building indicated the need for improvement of some elements flexural and shear capacities. As stated before, FRP-wrapping is widely recognised as an effective strategy for increasing the deformation and shear capacity of RC elements, without modifying the structure's stiffness [5], [23].

Following the advantages of this strengthening technique, a CFRP retrofitting strategy was developed and applied to the case study building to overcome its poor seismic performance.

The design of the CFRP solution was based on the attainment of the target displacement, for SD limit state, without failure of any vertical member. This means that chord rotation and shear capacities of the elements identified in Figure 5 need to be enhanced. Erro! A origem da referência não foi encontrada. shows the actual and required capacity values of chord rotation and shear of those elements.

The determination of the right amount of FRP to comply with the required values of capacity followed an iterative procedure: i) knowing the required capacity that each element needs to reach, an initial strengthening solution is adopted and the new chord rotation and shear capacity of each element is computed; ii) if the capacity values obtained are higher than the values indicated in Erro! A origem da referência não foi encontrada., a solution was achieved and applied to the structural model; iii) a new assessment is carried out. Otherwise, a new tentative strengthening solution needs to be considered and the procedure repeated. The new strengthening solution can be achieved by increasing the thickness of the CFRP sheet, the number of layers or upgrading the chosen FRP material.

\begin{tabular}{|c|c|c|c|c|c|c|}
\hline $\begin{array}{l}\text { Direc- } \\
\text { tion }\end{array}$ & $\begin{array}{l}\text { Vertical } \\
\text { element }\end{array}$ & $\begin{array}{c}\text { Failure } \\
\text { mecha- } \\
\text { nism }\end{array}$ & $\begin{array}{c}\text { Actual } \theta_{S D} \\
{[\%]}\end{array}$ & $\begin{array}{c}\text { Required } \theta_{S D} \\
{[\%]}\end{array}$ & $\begin{array}{l}\text { Actual } V_{R D} \\
{[\mathrm{kN}]}\end{array}$ & $\begin{array}{c}\text { Required } V_{R D} \\
\text { [Kn] }\end{array}$ \\
\hline \multirow{5}{*}{$X$} & C $\mathrm{C}_{3} \mathrm{~L} 0 \_\mathrm{X}$ & Brittle & - & - & 33.41 & 38.1 \\
\hline & $\mathrm{C}_{3} \mathrm{~L} 1{ }^{-} \mathrm{X}$ & Brittle & - & - & 33.0 & 35.8 \\
\hline & $\mathrm{C}_{6} \mathrm{~L} 1{ }^{-} \mathrm{X}$ & Brittle & - & - & 28.31 & 30.05 \\
\hline & $\mathrm{C}_{8} \mathrm{~L}^{-1} \mathrm{X} \mathrm{X}$ & Brittle & - & - & 88.5 & 90.2 \\
\hline & $\mathrm{W}_{1} \mathrm{L1}^{-} \mathrm{X}$ & Ductile & 1.26 & 1.33 & - & - \\
\hline \multirow{3}{*}{ Y } & $\mathrm{C}_{2} \mathrm{~L} 0 \_\mathrm{Y}$ & Brittle & - & - & 111.7 & 128.3 \\
\hline & $\mathrm{C}_{3} \mathrm{LO}^{-} \mathrm{Y}$ & Brittle & & & 111.7 & 128.6 \\
\hline & $\mathrm{W}_{1} \mathrm{LO} 0 \_\mathrm{Y}$ & Brittle & - & - & 78.4 & 90.7 \\
\hline
\end{tabular}

Table 5: Actual and required capacity values of chord rotation and shear for the damaged elements

From the iterative procedure depicted above, one layer of CFRP (with the properties described in Erro! A origem da referência não foi encontrada.) was found to be enough to provide the desired capacity to retrofit the identified structural elements. Since these elements are subjected to a constant shear demand, the CFRP sheets were modelled as uniformly applied through the height of the element [24]. However, due to architectural constraints, the U-shaped or side bonded striped FRPs are, in some cases, the only possible solution. To avoid the fibres premature rupture, the corners of the elements were assumed to be rounded, with a radius of 4 $\mathrm{cm}$ and, to improve the shear capacity of the elements, the CFRP sheets were considered to be applied with the fibres aligned along the direction in which enhancement of shear strength is pursued (i.e. horizontal) [25], [26]. 


\begin{tabular}{ccccc}
\hline $\begin{array}{c}\text { Fiber thickness } t_{f} \\
{[\mathrm{~mm}]}\end{array}$ & $\begin{array}{c}\text { Tensile Strength } \\
f_{u, f}[\mathrm{MPa}]\end{array}$ & $\begin{array}{c}\text { Tensile Modulus } \\
E_{f}[\mathrm{MPa}]\end{array}$ & Elongation [\%] & $\begin{array}{c}\text { Ultimate strain } \\
\varepsilon_{u, f}\end{array}$ \\
\hline 0.128 & 3450 & 230000 & 1.5 & 0.0015 \\
\hline
\end{tabular}

Table 6: Properties of the CFRP [27]

Regarding the modelling of the retrofitted solution, the contribution of the CFRP was considered through the increase of the confinement of the retrofitted elements. The core and cover materials of these elements were replaced with an equivalent material with the properties calculated by means of Equations (1) and (3). The model of the building remains the same, except for the retrofitted elements.

\subsection{Assessment of the retrofitted building}

Finished the design and modelling of the retrofitting solution, a new assessment was performed to the structure to evaluate the effectiveness of the adopted solution. A pushover analysis was again carried out to evaluate the lateral capacity of the structure. Figure 6 shows a comparison between the pushover curves obtained before (pre-retrofit) and after (post- retrofit) applying the CFRP. As it can be seen, the application of the CFRP contributed to an increase of the lateral strength of the structure, in both the $\mathrm{X}$ and $\mathrm{Y}$ directions, without modifying its initial stiffness. However, the structure's capacity improvement is significantly higher in the $\mathrm{X}$ direction in comparison with the Y direction. This is due to fact the RC walls, which were strengthened at the first and second storey levels, are oriented in the $\mathrm{X}$ direction.

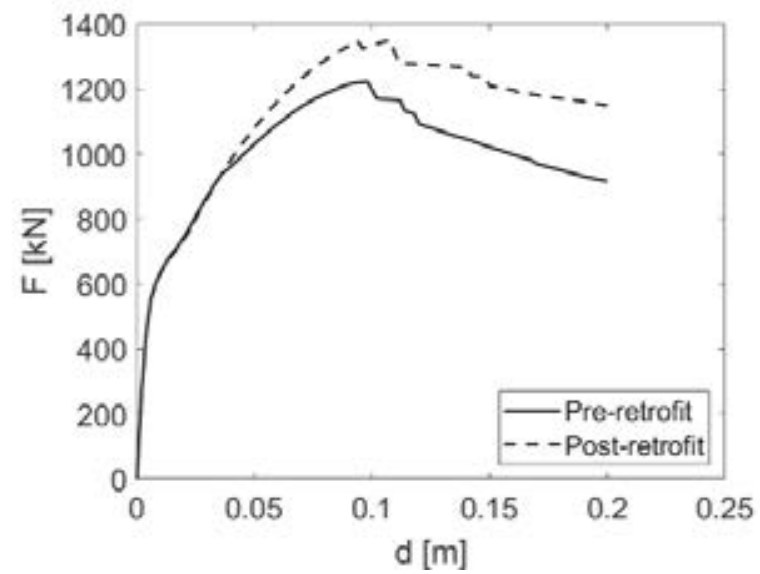

(a)

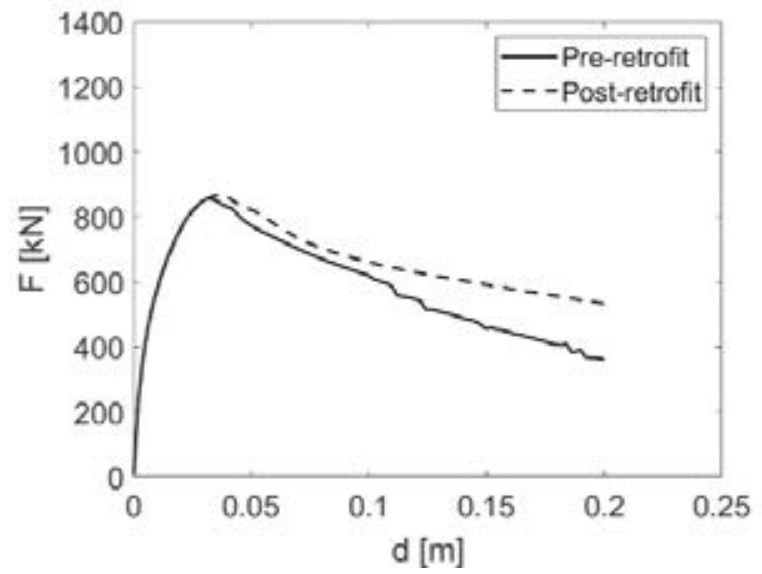

(b)

Figure 6: Pushover curves obtained pre and post retrofitting for the (a) X and (b) Y direction.

A safety assessment was also carried out in terms of demand/capacity ratio evaluation (DCR) for each vertical structural element, as established in EC8-3. Figure 7 shows the pushover curves obtained for the $\mathrm{X}$ and $\mathrm{Y}$ directions with the indication of the target displacement that corresponds to the attainment of the SD limit state. In the X direction, the development of a mechanism, either brittle or ductile, still occurs but only after the target displacement is reached. On the other hand, in the Y direction, the columns' brittle failure is not expected to develop, 
and the ductile mechanism occurs for a top displacement much higher than the target displacement. These results confirm the efficiency of the CFRP and its effect in the improvement of the structure's seismic performance.

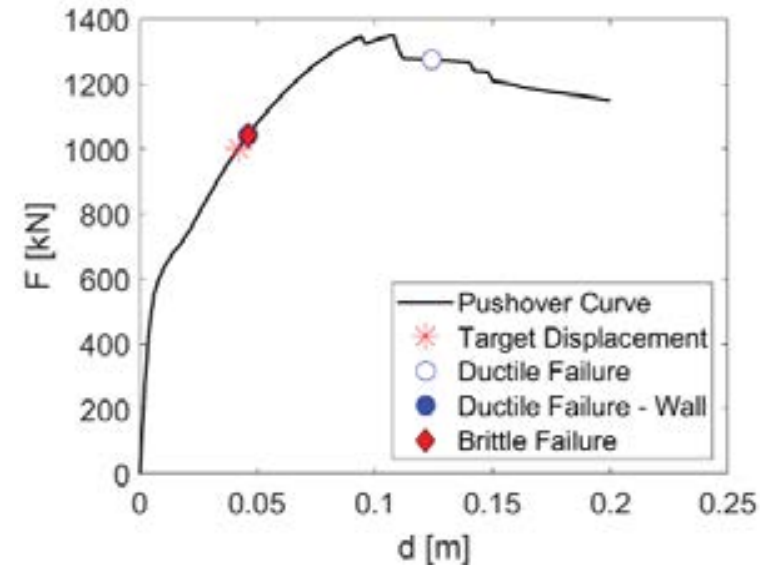

(a)

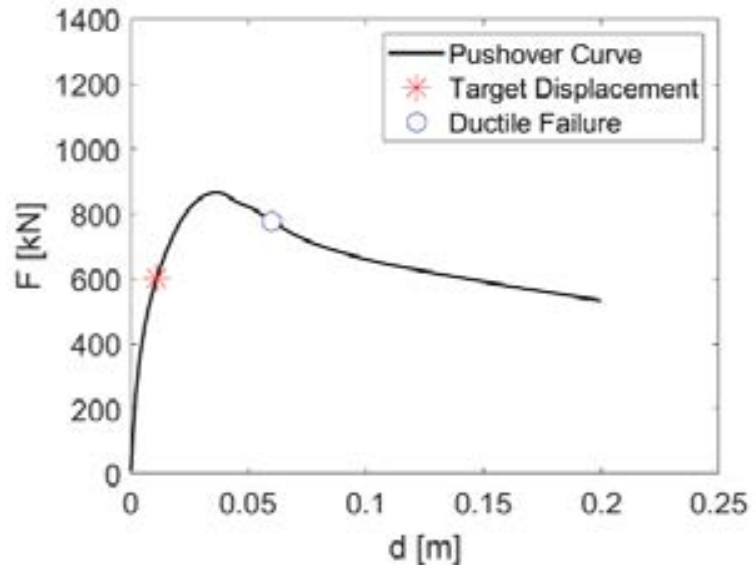

(b)

Figure 7: Pushover curves of the retrofitted structure for the (a) X and (b) Y direction with the indication of the target displacement and failure mechanisms.

\section{CONCLUSIONS}

This paper focused on the modelling of retrofitting solutions with carbon fibre-reinforced polymers (CFRP) to improve the seismic performance of RC structures. The first part of this research consisted of a proposal of a modelling approach to retrofit RC elements with CFRP. The CFRP was included in the model through the increase of the element's cross-section confinement.

The core and cover materials of retrofitted element were replaced with an equivalent material, whose properties were determined using the confinement model proposed in EC8-3. Afterwards, the modelling approach was validated against experimental data. The results showed a good agreement between the numerical and experimental data, indicating that the modelling approach is adequate to model FRP interventions in existing RC buildings.

The second part of this investigation focused on the application of the proposed modelling approach to an existing $\mathrm{RC}$ building. The selected structure corresponds to a residential building built before the introduction of modern codes without appropriate seismic resistance and characterized by (i) low confinement and tie reinforcement in vertical structural elements; (ii) insufficient longitudinal reinforcement in all structural elements; (iii) smooth longitudinal reinforcement rebars; (iv) variation in height of the vertical structural elements section and v) absence of masonry infills at the ground level. Non-linear static analyses were carried out and a seismic evaluation was performed in terms of the demand/capacity ratio (DCR), following the procedure recommended in EC8-3. This assessment exposed brittle and ductile failures in some structural elements. A retrofitting solution employing CFRP was designed and implemented numerically in the structure's model. The comparison between the pre- and post-retrofit pushover curves showed a clear improvement on the buildings' lateral strength, mainly on the $\mathrm{X}$ direction due to the retrofitting of the $\mathrm{RC}$ walls which control the behaviour of the structure in this direction. Additionally, the seismic safety of the structure, represented by the attainment of the target displacement at SD limit state without the occurrence of any failure mechanism, 
highlights the effectiveness not only of the modelling approach but also of the adopted retrofitting solution.

\section{ACKNOWLEDGMENTS}

The authors would like to acknowledge the financial support of Fundação para a Ciência e a Tecnologia (FCT, Ministério da Educação e Ciência, Portugal) through the FCT Research Program: MitRisk - Framework for seismic risk reduction resorting to cost-effective retrofitting solutions, POCI-01-01456-Feder-031865.

\section{REFERENCES}

[1] M. Del Zoppo, M. Di Ludovico, A. Balsamo, A. Prota, and G. Manfredi, "FRP for seismic strengthening of shear controlled RC columns: Experience from earthquakes and experimental analysis," Compos. Part B Eng., vol. 129, pp. 47-57, 2017.

[2] G. M. Verderame, F. De Luca, P. Ricci, and G. Manfredi, "Preliminary analysis of a soft-storey mechanism after the 2009 L'Aquila earthquake," Earthq. Eng. Struct. Dyn., vol. 40, pp. 925-944, 2011.

[3] F. De Luca, G. M. Verderame, F. Gómez-Martínez, and A. Pérez-García, “The structural role played by masonry infills on RC building performances after the 2011 Lorca, Spain, earthquake,” Bull. Earthq. Eng., vol. 12, no. 5, pp. 1999-2026, 2014.

[4] J. G. Ruiz-Pinilla, J. M. Adam, R. Pérez-Cárcel, J. Yuste, and J. J. Moragues, "Learning from RC building structures damaged by the earthquake in Lorca, Spain, in 2011," Eng. Fail. Anal., vol. 68, pp. 76-86, Oct. 2016.

[5] A. S. Elnashai and R. Pinho, "Repair and retrofitting of rc walls using selective techniques," J. Earthq. Eng., vol. 2, no. 4, pp. 525-568, 1998.

[6] R. Ma, Y. Xiao, and K. N. Li, "Full-scale testing of a parking structure column retrofitted with carbon fiber reinforced composites," Constr. Build. Mater., 2000.

[7] L. P. Ye, K. Zhang, S. H. Zhao, and P. Feng, "Experimental study on seismic strengthening of RC columns with wrapped CFRP sheets," 2003.

[8] K. Galal, A. Arafa, and A. Ghobarah, "Retrofit of RC square short columns," Eng. Struct., 2005.

[9] C. Yalcin, O. Kaya, and M. Sinangil, "Seismic retrofitting of R/C columns having plain rebars using CFRP sheets for improved strength and ductility," Constr. Build. Mater., 2008.

[10] M. ElGawady, M. Endeshaw, D. McLean, and R. Sack, "Retrofitting of Rectangular Columns with Deficient Lap Splices," J. Compos. Constr., 2010.

[11] D. A. Bournas and T. C. Triantafillou, "Bond Strength of Lap-Spliced Bars in Concrete Confined with Composite Jackets," J. Compos. Constr., 2011.

[12] R. Realfonzo and A. Napoli, "Results from cyclic tests on high aspect ratio RC columns strengthened with FRP systems," Constr. Build. Mater., 2012. 
[13] H. F. Ghatte, M. Comert, C. Demir, and A. Ilki, "Evaluation of FRP confinement models for substandard rectangular RC columns based on full-scale reversed cyclic lateral loading tests in strong and weak directions," Polymers (Basel)., 2016.

[14] F. McKenna, G. Fenves, and M. Scott, "OpenSees: open system for earthquake engineering simulation," Pacific Earthquake Engineering Research Center, University of California, Berkeley, 2007. .

[15] CEN, "European Standard EN 1998-3:2005: Design of structures for earthquake resistance - Part 3: Assessment and retrofitting of buildings," Com. Eur. Norm. Brussels, 2005.

[16] M. Del Zoppo, M. Di Ludovico, A. Balsamo, and A. Prota, "Comparative analysis of existing RC columns jacketed with CFRP or FRCC," Polymers (Basel)., 2018.

[17] S. Popovics, "A numerical approach to the complete stress-strain curve of concrete," Cem. Concr. Res., vol. 3, no. 5, pp. 583-599, 1973.

[18] C. Caruso, R. Bento, R. Sousa, and A. A. Correia, "Modelling strain penetration effects in RC walls with smooth steel bars," Mag. Concr. Res., vol. 71, no. 17, pp. 894-906, 2019.

[19] D. Celarec, P. Ricci, and M. Dolšek, "The sensitivity of seismic response parameters to the uncertain modelling variables of masonry-infilled reinforced concrete frames," Eng. Struct., vol. 35, pp. 165-177, 2012.

[20] CEN, "EN 1998-1. Eurocode 8 - Design of structures for earthquake resistance - Part 1: General rules, seismic actions and rules for buildings," Eur. Comm. Stand., 2004.

[21] CEN, "European Standard NP EN 1998-3: Eurocódigo 8 - Projecto de estruturas para resistência ao sismo. Parte 3: Avaliação e Reabilitação de edifícios.," Inst. Port. da Qualidade. Eur. Comm. Stand., 2017.

[22] C. M. Ramirez and E. Miranda, "Building-specific loss estimation methods \& tools for simplified performance-based. Report No. 171," , Blume Center Report. Edited by T. J. A. B. E. E. Center. Stanford, CA., 2009.

[23] C. Caruso, "Definition of mitigation strategies for the seismic risk reduction of old RC residential buildings," Universidade de Lisboa, Instituto Superior Técnico, 2019.

[24] C. Caruso, "Feasibility of Retrofitting Solutions for an Old Rc Wall-Frame Building in Lisbon," pp. 1-12, 2019.

[25] M. N. Fardis, "Seismic Design, Assessment and Retrofitting of Concrete Buildings," Geotech. Geol. Earthq. Eng., 2009.

[26] B. Li and C. L. Lim, "Tests on Seismically Damaged Reinforced Concrete Structural Walls Repaired Using Fiber-Reinforced Polymers," J. Compos. Constr., vol. 14, no. 5, pp. 597-608, 2010.

[27] Sika, "SikaWrap ${ }^{\circledR}$ Hex-230 C." 